\section{BMJ Paediatrics Open}

\title{
Retrospective study of haemophagocytic syndrome hospitalisations in children in the USA
}

\author{
Aditya Badheka, ${ }^{1}$ Pradeep Bangalore Prakash, ${ }^{2}$ Veerasathpurush Allareddy, ${ }^{3}$ \\ Veerajalandhar Allareddy ${ }^{4}$
}

To cite: Badheka A, Bangalore Prakash $P$, Allareddy V, et al. Retrospective study of haemophagocytic syndrome hospitalisations in children in the USA. BMJ Paediatrics Open 2018;2:e000337. doi:10.1136/ bmjpo-2018-000337

Limited results of this study were presented as a poster at American Academy of Pediatrics-Society of Critical Care Colloquium meeting at Chicago, Illinois, USA (September 2017).

Received 18 June 2018 Revised 15 0ctober 2018 Accepted 16 October 2018

Check for updates

\section{(C) Author(s) (or their} employer(s)) 2018. Re-use permitted under CC BY-NC. No commercial re-use. See rights and permissions. Published by BMJ.

${ }^{1}$ Pediatric Critical Care, Stead Family Children's Hospital, University of lowa, lowa City, Iowa, USA

${ }^{2}$ Mercy Medical Center, Des Moines, lowa, USA

${ }^{3}$ Department of Orthodontics, College of Dentistry, University of Illinois at Chicago, Chicago, Illinois, USA

${ }^{4}$ Division of Pediatric Critical Care, Duke Children's Hospital, Duke University, Durham, North Carolina, USA

Correspondence to Dr Aditya Badheka; adityabadheka@uiowa.edu

\section{ABSTRACT}

Introduction The haemophagocytic syndrome (HS) is a rare condition that presents with uncontrolled inflammation leading to multiorgan failure and is associated with significant morbidity and mortality. Current national estimates of children hospitalised due to HS are unknown. Characterising and understanding the burden of HS-related hospitalisations at a national level is the initial step in optimising the overall care.

Methods We performed a retrospective analysis of the Nationwide Inpatient Sample (NIS) from 2012 to 2014. The NIS is the largest all-payer inpatient care dataset in the USA that contains more than seven million hospital stays and its large sample size is ideal for developing national estimates of rare conditions. All patients aged up to 18 years who were primarily hospitalised due to HS were selected for our study. Descriptive statistics were used. A multitude of patient-level and hospital-level variables were assessed. Outcome variables included overall in-hospital mortality, hospital charges and the length of stay.

Results A total of 840 patients aged up to 18 years were hospitalised primarily due to HS in the USA. Mean age was 5.7 years. $57.4 \%$ were males. Whites comprised $45 \% .6 .5 \%$ died in hospital. A vast majority (78\%) were admitted on an emergency/urgent basis. The most frequent payers included Medicaid (50\%) and private insurance (36.9\%). Almost $80 \%$ of children had at least one comorbid condition. $96.3 \%$ of patients were treated in urban teaching hospitals. Southern regions accounted for $42.6 \%$ of all hospitalisations. The median length of stay in hospital was 9.6 days and the median hospitalisation charge was US\$100 426.

Conclusion Nearly 1 in 15 children who were hospitalised due to HS died. The resource utilisation associated with HS-related hospitalisations is considerable. The majority of hospitalised children with HS had comorbid conditions.

\section{INTRODUCTION}

The haemophagocytic syndrome (HS) is an umbrella term which includes haemophagocytic lymphohistiocytosis (HLH), macrophage activation syndrome (MAS) and haemophagocytic reticulosis (HLS). This group of disorder results in uncontrolled life-threatening systemic inflammation. HS leads to cytokine storms which result in

\section{What is already known on this topic?}

Haemophagocytic syndromes (HSs) are a group of disorders resulting in uncontrolled systemic inflammation and associated with significant morbidity and mortality.

- International Histiocyte Society proposed revised criteria to diagnose HS with clinical, laboratory and pathology features.

\section{What this study hopes to add?}

In this large epidemiological study, nearly 1 in 15 children hospitalised with haemophagocytic syndrome died.

- The hospitalisation is associated with significant resource utilisation.

unchecked stimulation of the immune system with excessive proinflammatory stimuli and inadequate immune regulation. ${ }^{1}$ The aetiology includes genetic mutation, rheumatological conditions (ie, systemic juvenile idiopathic arthritis, lupus), malignancy and infections (ie, Cytomegalovirus, Epstein-Barr virus, HIV, Staphylococci, gram-negative sepsis, Mycobacterium, histoplasma, malaria). ${ }^{1}$ The usual presentation mimics severe sepsis with multiorgan dysfunction. ${ }^{2}$ The uncontrolled inflammation leads to multiorgan dysfunction and associated with significant morbidity and mortality. ${ }^{2}$ The International Histiocyte Society revised criteria for the diagnosis of both familial and reactive HLH (box 1). ${ }^{3}$ The diagnosis of HS remained clinical, supported by elevation of inflammatory markers, that is, ferritin $>10000 \mathrm{mg} / \mathrm{dL}$, elevated soluble Interleukin-2 (IL-2) receptor and low natural killer cell (NK-cell) activity. Bone marrow examination may show haemophagocytosis but is not required for diagnosis. ${ }^{2}$ Cardiac involvement is rare, most commonly involved organs are liver and kidneys. The management of HS is not standardised. The goal of 
Box 1 Revised diagnostic guidelines for

haemophagocytic lymphohistiocytosis (HLH)

The diagnosis HLH can be established if one of either 1 or 2 below is fulfilled

1. A molecular diagnosis consistent with HLH.

2. Diagnostic criteria for HLH fulfilled (five out of the eight criteria below).

(A) Initial diagnostic criteria (to be evaluated in all patients with HLH)

$\checkmark$ Fever.

- Splenomegaly.

- Cytopenias (affecting $\geq 2$ of 3 lineages in the peripheral blood).

- Haemoglobin $<9 \mathrm{~g} / \mathrm{dL}$ (in infants $<4$ weeks: haemoglobin $<10 \mathrm{~g} / \mathrm{dL}$ ).

- Platelets $<100 \times 10^{9} / \mathrm{L}$.

- Neutrophils $<1.0 \times 10^{9} / \mathrm{L}$.

- Hypertriglyceridaemia and/or hypofibrinogenaemia:

- Fasting triglycerides $\geq 3.0 \mathrm{mmol} / \mathrm{L}$ (ie, $\geq 265 \mathrm{mg} / \mathrm{dL}$ ).

- Fibrinogen $\leq 1.5 \mathrm{~g} / \mathrm{L}$.

- Haemophagocytosis in bone marrow or spleen or lymph nodes.

- No evidence of malignancy.

(B) New diagnostic criteria

- Low or absent NK-cell activity (according to local laboratory reference).

- Ferritin $\geq 500 \mu \mathrm{g} / \mathrm{L}$.

Soluble CD25 (ie, soluble IL-2 receptor) $\geq 2400 \mathrm{U} / \mathrm{mL}$.

therapy is the restoration of immune homoeostasis and elimination of offending aetiology. ${ }^{4}$ The current national estimates with HS-related hospitalisation and its associated outcomes in children is unknown. We aim to characterise and understand the burden of HS-related hospitalisations and related outcomes by using the nationwide sample.

\section{MATERIALS AND METHODS}

We performed a retrospective analysis of the Nationwide Inpatient Sample (NIS) for the years 2012-2014. The NIS is the largest all-payer nationally representative sample of all hospitalisations in the USA. NIS is one of the component databases of the Healthcare Cost and Utilization Project (HCUP) of the Agency for Healthcare Research and Quality (AHRQ). ${ }^{5}$ The NIS was obtained following completion of a data user agreement with HCUP-AHRQ. It provides information on well over 100 patient-level/ hospital-level variables and has been used to examine outcomes associated with uncommon conditions. The NIS is a $20 \%$ stratified sample of all hospitalisations and each discharge is assigned a discharge weight that can be used to project to national estimates. The study used data that was de-identified of any unique patient identifiers. All patients who were hospitalised due to HS (primary diagnosis) were included in the present study. The International Classification of Diseases, Ninth Revision, Clinical Modification (ICD-9-CM) diagnosis code of 288.4 was used to identify this cohort. ${ }^{6}$ The variables that were examined included age at the time of admission, sex, race, insurance status (any governmental insurance programmes, private insurance or uninsured), comorbid burden, type of admission, hospital-level variables, length of stay in the hospital and hospitalisation charges. Comorbid burden severity was assessed by using the NIS comorbid severity files. ${ }^{5}$ NIS severity files provide data on presence of multiple comorbid conditions (deficiency anaemias, rheumatoid arthritis/collagen vascular diseases, chronic blood loss anaemia, congestive heart failure, chronic pulmonary disease, coagulopathy, diabetes-uncomplicated, diabetes-with complications, hypertension, liver disease, lymphoma, fluid and electrolyte disorders, metastatic cancer, neurological disorders, obesity, paralysis, peripheral vascular disorders, pulmonary circulation disorders, renal failure, solid tumour without metastasis, peptic ulcer disease excluding bleeding, valvular disease, and weight loss). The comorbid burden was computed by summing the presence of each comorbid condition. Hospitalisation charges were inflation adjusted to the year 2014 levels using the Bureau of Labor Statistics inflation rates for healthcare. ${ }^{7}$

\section{DATABASE}

HCUP NIS. HCUP 2012. AHRQ, Rockville, MD www. hcup-us.ahrq.gov/nisoverview.jsp.

\section{RESULTS}

A total of 840 patients aged up to 18 years were hospitalised primarily due to HSs in the USA during the years 2012-2014. The mean age was 6 years and the median age was 3.3 years (the IQR was 0.4 years and 10.7 years). The overall distribution of age is summarised in figure 1 . $19.6 \%$ were aged less than 1 year, $14.9 \%$ were aged 1 year and $9.5 \%$ were 2 years. The characteristics of patients are summarised in table $1.51 .8 \%$ of patients were males. A vast majority $(78 \%)$ were admitted on an emergency/ urgent basis. Caucasians comprised $41.2 \%$ of patients

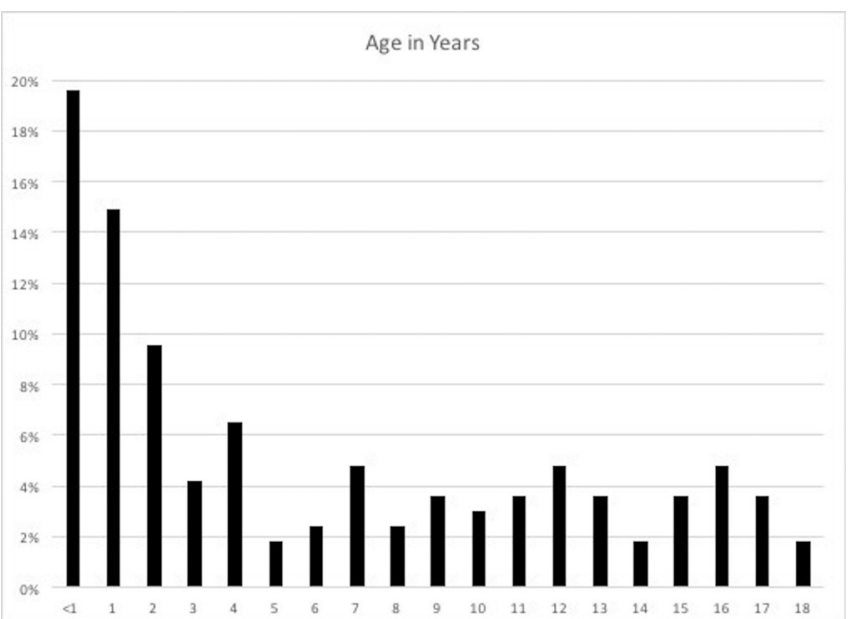

Figure 1 Distribution of Age of Hospitalized children with HLH from 2012 to 2014. 
Table 1 Characteristics of patients (aged up to 18 years) hospitalised due to haemophagocytic syndromes (years 2012-2014)

\begin{tabular}{ll}
\hline Characteristics & Total $\mathbf{n = 8 4 0 , ( \% )}$ \\
\hline Sex & \\
\hline Male & $435(51.8)$ \\
\hline Female & $405(48.2)$ \\
\hline Type of admission & \\
\hline Emergency/urgent & $655(78)$ \\
\hline Elective & $185(22)$ \\
\hline Disposition status & \\
\hline Routine & $645(76.8)$ \\
\hline Transfer to another short-term hospital & $45(5.4)$ \\
\hline Transfer to long-term care facility & DS* \\
\hline Home healthcare & $90(10.7)$ \\
\hline Died in hospital & $45(5.4)$ \\
Unknown destination & DS*
\end{tabular}

Race (information on race is available for

765 hospitalisations)

\begin{tabular}{|c|c|}
\hline Caucasian & $315(41.2)$ \\
\hline African American & $125(16.3)$ \\
\hline Hispanic & $205(26.8)$ \\
\hline Asian/Pacific Islander & $75(9.8)$ \\
\hline Other races & $45(5.9)$ \\
\hline \multicolumn{2}{|l|}{ Insurance status } \\
\hline Medicare & $\mathrm{DS}^{*}$ \\
\hline Medicaid & $420(50)$ \\
\hline Private & $310(36.9)$ \\
\hline Uninsured & $\mathrm{DS}^{*}$ \\
\hline Other insurance & 95 (11.3) \\
\hline \multicolumn{2}{|l|}{ Hospital region } \\
\hline Northeast & $130(15.5)$ \\
\hline Midwest & $175(20.8)$ \\
\hline South & $360(42.9)$ \\
\hline West & $175(20.8)$ \\
\hline Urban non-teaching hospital & $30(3.6)$ \\
\hline Urban teaching hospital & $810(96.4)$ \\
\hline \multicolumn{2}{|l|}{ Length of stay in hospital } \\
\hline Mean & 22.1 days \\
\hline Median & 9.6 days \\
\hline 25th percentile & 3.1 days \\
\hline 75th percentile & 26.5 days \\
\hline \multicolumn{2}{|c|}{ Hospital charges (adjusted to year 2014 US\$ value) } \\
\hline Mean & US $\$ 330658$ \\
\hline Median & US\$100 426 \\
\hline 25th percentile & US\$32327 \\
\hline 75th percentile & US\$264288 \\
\hline
\end{tabular}

${ }^{*}$ As per the data user agreement (author- Agency for Healthcare Research and Quality), cell counts $\leq 10$ cannot be reported to maintain patient and hospital privacy. In accordance with the agreement, low cell counts were not reported and the term 'DS' (discharge information suppressed) was used instead.
Table 2 Characteristics of the comorbid conditions of hospitalised patients ( $<18$ years old) with haemophagocytic syndromes (years 2012-2014)

\begin{tabular}{|c|c|}
\hline Case mix characteristic & Total $n=840,(\%)$ \\
\hline Fluid and electrolyte disorders & $330(39.3)$ \\
\hline Hypertension & $295(35.1)$ \\
\hline Coagulopathy & $290(34.5)$ \\
\hline Deficiency anaemias & $190(22.6)$ \\
\hline Adverse effects of medical drugs & $155(18.4)$ \\
\hline Sepsis & $130(15.5)$ \\
\hline $\begin{array}{l}\text { Rheumatoid arthritis/collagen vascular } \\
\text { diseases }\end{array}$ & $90(10.7)$ \\
\hline Bacterial infections & $70(8.3)$ \\
\hline Liver disease & $60(7.1)$ \\
\hline Neurological disorders & $50(5.9)$ \\
\hline Obesity & $45(5.4)$ \\
\hline Weight loss & $25(3)$ \\
\hline Renal failure & $20(2.4)$ \\
\hline Depression & $15(1.8)$ \\
\hline Diabetes_uncomplicated & $15(1.8)$ \\
\hline Psychoses & $15(1.8)$ \\
\hline Valvular diseases & $15(1.8)$ \\
\hline Diabetes with chronic complications & DS \\
\hline Drug abuse & DS \\
\hline Hypothyroidism & DS \\
\hline Lymphoma & DS \\
\hline Paralysis & DS \\
\hline Pulmonary circulation disorders & DS \\
\hline
\end{tabular}

DS, As per the data user agreement (author- Agency for Healthcare Research and Quality), cell counts $\leq 10$ cannot be reported to maintain patient and hospital privacy. In accordance with the agreement, low cell counts were not reported and the term 'DS' (discharge information suppressed) was used instead.

followed by Hispanics (26.8\%), African-Americans $(16.3 \%)$, Asians/Pacific Islanders $(9.8 \%)$ and other races $(5.9 \%)$. Following hospitalisation, $76.8 \%$ were discharged routinely, $5.4 \%$ were transferred to another hospital and $10.7 \%$ were discharged to home healthcare. $5.4 \%$ died in hospitals. The most frequent payers included Medicaid $(50 \%)$ and private insurance plans $(36.9 \%)$. Close to $80 \%$ of patients had at least one comorbid condition. The characteristic of hospitalised patients with a primary diagnosis of HLH and comorbid condition are summarised in table 2. Fluid and electrolyte disorders $(39.3 \%)$, hypertension $(35.1 \%)$, coagulopathy $(34.5 \%)$, deficiency anaemia $(22.6 \%)$ and adverse reaction to medical drugs $(18.4 \%)$ were most common associated comorbidities. In addition, sepsis $(15.5 \%)$, bacterial infections $(8.3 \%)$, rheumatological arthritis/collagenvascular disorders $(10.7 \%)$ and liver disease $(7.1 \%)$ were most frequently observed conditions in hospitalised patients with primary diagnosis of HLH (table 2). 


\begin{tabular}{ll} 
Table 3 & Comorbid burden \\
\hline Comorbid burden & Total $\mathbf{n = 8 4 0 , ( \% )}$ \\
\hline 0 & $170(20.2)$ \\
1 & $215(25.6)$ \\
2 & $205(24.4)$ \\
3 & $135(16.1)$ \\
4 & $65(7.7)$ \\
$\geq 5$ & $50(6)$ \\
\hline
\end{tabular}

Comorbid burden was computed by summing the occurrence of 29 different comorbid conditions obtained from the NIS disease severity files. The comorbid conditions examined included: AIDS, alcohol abuse, deficiency anaemias, rheumatoid arthritis/collagen vascular diseases, chronic blood loss anaemia, congestive heart failure, chronic pulmonary disease, coagulopathy, depression, diabetes-uncomplicated, diabetes-with chronic complications, drug abuse, hypertension, hypothyroidism, liver disease, lymphoma, fluid and electrolyte disorders, metastatic cancer, neurological disorders, obesity paralysis, peripheral vascular disorders, psychoses, pulmonary circulatory disorders, renal failure, solid tumour without metastasis, peptic ulcer disease, valvular disease, and weight loss.

NIS, Nationwide Inpatient Sample.

The distribution of comorbid burden is summarised in table 3. Overall, $25.6 \%$ had at least one comorbid condition, $24.4 \%$ had two conditions, $16.1 \%$ had three conditions, $7.7 \%$ had four conditions and $6 \%$ had five or more conditions (table 3). 96.4\% of patients were treated in urban teaching hospitals. Southern regions accounted for $42.9 \%$ of all hospitalisations while Midwest (20.8\%), West $(20.8 \%)$ and Northeast $(15.5 \%)$ accounted for rest. The mean length of stay in hospital was 22.1 days (median is 9.6 days, the IQR is 3.1-26.5 days) and the mean hospitalisation charge was US\$3 30658 (median is US\$100 426, the IQR is US\$32327-US\$264 288).

\section{DISCUSSION}

The data collected in the study showed the prevalence of HS is higher in infancy $(34.5 \%)$ with a slightly higher incidence in men $(51.2 \%$ vs $48.8 \%)$. The majority admitted on an emergent/urgentbasis, which may be explained by a rapidly progressive sepsis-like presentation with multiple organ involvement. In this cohort, the majority had at least one comorbid condition and managed in the urban teaching hospitals. Interestingly, the majority of HS admissions are from the Southern regions of the USA. It is important to understand that the clinical picture of HS overlap and shares several features with MAS, multi-organ dysfunction syndrome (MODS) and sepsis. ${ }^{8}$ The revised diagnostic criteria proposed by the American Histiocyte Society in 2004 is based mainly on clinical picture supported by laboratory investigations. ${ }^{3}$ It has been demonstrated that these criteria fail to reliably discriminate HS from other syndromes. ${ }^{29}$ In the Turkish paediatric cohort, the reported mortality of $57 \%$ in critically ill paediatric patients with HLH and MODS. ${ }^{10}$
Another HLH series of 20 patients demonstrated the mortality rate of $60 \% .{ }^{11}$ The nationwide sampling during this study showed mortality rates of $5.4 \%$, still significant but lower than reported in the literature.

To our knowledge, the present study is the first and largest epidemiological estimates of HS associated hospitalisations in children in the USA. Results from this study can be generalised, which to an extent, negates the limitations of the single centre experiences. A multitude of patient-level and hospital-level variables were examined in this study and is the first study to assess resource utilisation associated with HS hospitalisations at a national level.

There are limitations to our study. As with any large administrative datasets, potential coding errors are possible, and this could underestimate the true impact of HS. However, the NIS is well designed and validated for estimating outcomes of rare diagnosis. ${ }^{5}$ The retrospective design of the study precludes us from drawing a true causation. Nearly $16 \%$ of the patients with HS were discharged to another short-term facility or home healthcare-this could again underestimate the resource utilisation associated with HS.

\section{CONCLUSIONS}

In this large epidemiological study, infants and toddlers accounted for the majority of children who were hospitalised due to HS. Eighty per cent of children with HS had associated comorbid conditions. Most of these children were managed in urban teaching hospitals. Death due to HS is not an infrequent occurrence. HS is associated with considerable resource utilisation.

Contributors Conceived and/or designed the work that led to the submission, acquired data and/or played an important role in interpreting the results: $A B$, VjA, VsA and PBP. Drafted and/ or revised the manuscript: AB, VjA, VsA and PBP. Approved the final version. AB, VjA, VsA and PBP.

Funding The authors have not declared a specific grant for this research from any funding agency in the public, commercial or not-for-profit sectors.

Competing interests None declared.

Patient consent Not required.

Ethics approval The study was deemed to not meet the regulatory requirements of human subjects research by the Office of Human Subjects Research-The University of lowa and hence IRB approval was not needed.

Provenance and peer review Not commissioned; externally peer reviewed.

Open access This is an open access article distributed in accordance with the Creative Commons Attribution Non Commercial (CC BY-NC 4.0) license, which permits others to distribute, remix, adapt, build upon this work non-commercially, and license their derivative works on different terms, provided the original work is properly cited, appropriate credit is given, any changes made indicated, and the use is non-commercial. See: http://creativecommons.org/licenses/by-nc/4.0/

\section{REFERENCES}

1. Tisoncik JR, Korth MJ, Simmons CP, et al. Into the eye of the cytokine storm. Microbiol Mol Biol Rev 2012;76:16-32.

2. Castillo L, Carcillo J. Secondary hemophagocytic lymphohistiocytosis and severe sepsis/ systemic inflammatory response syndrome/multiorgan dysfunction syndrome/macrophage activation syndrome share common intermediate phenotypes on a spectrum of inflammation. Pediatr Crit Care Med 2009;10:387-92. 
3. Henter JI, Horne A, Aricó M, et al. HLH-2004: diagnostic and therapeutic guidelines for hemophagocytic lymphohistiocytosis. Pediatr Blood Cancer 2007;48:124-31.

4. Carcillo JA, Sward K, Halstead ES, et al. A systemic inflammation mortality risk assessment contingency table for severe sepsis. Pediatr Crit Care Med 2017;18:143-50.

5. Nationwide Inpatient Sample (NIS). Healthcare Cost and Utilization Project (HCUP). 2012-2014. Rockville, MD: Agency for Healthcare Research and Quality.

6. Centers for Disease Control and Prevention. Classification of diseases, functioning, and disability. International Classification of Diseases, Ninth Revision, Clinical Modification (ICD-9-CM). www. cdc.gov/nchs/icd/icd9cm.htm\#ftp (Accessed 03 Jun 2014).

7. Bureau of Labor Statistics. Medical care services in U.S. city average, all urban consumers, not seasonally adjusted. www.bls.gov (accessed is 06 Oct 2017).
8. Kuwata K, Yamada S, Kinuwaki E, et al. Peripheral hemophagocytosis: an early indicator of advanced systemic inflammatory response syndrome/hemophagocytic syndrome. Shock 2006;25:344-50.

9. Buyse S, Teixeira L, Galicier L, et al. Critical care management of patients with hemophagocytic lymphohistiocytosis. Intensive Care Med 2010;36:1695-702.

10. Karapinar B, Yilmaz D, Balkan C, et al. An unusual cause of multiple organ dysfunction syndrome in the pediatric intensive care unit: hemophagocytic lymphohistiocytosis. Pediatr Crit Care Med 2009;10:285-90.

11. Sung L, King SM, Carcao M, et al. Adverse outcomes in primary hemophagocytic lymphohistiocytosis. J Pediatr Hematol Oncol 2002;24:550-4. 